\title{
NARINGIN ATTENUATES OXIDATIVE STRESS AND PROTECT AGAINST MYOCARDIAL ISCHEMIA-REPERFUSION INJURY IN DIABETIC RAT
}

\author{
NEELAM KUMARI, AJAY SINGH KUSHWAH* \\ Department of Pharmacology, Amar Shaheed Baba Ajit Singh Jujhar Singh Memorial College of Pharmacy, Ropar, Punjab, India. \\ Email: kushwah_ph05@yahoo.co.in
}

Received: 15 November 2018, Revised and Accepted: 15 December 2018

\section{ABSTRACT}

Objective: The relative risk of coronary heart disease in diabetic patients is more than in non-diabetic population. The present study was undertaken to explore the cardioprotective effect of Naringin on ischemia-reperfusion injury in the diabetic model of rat.

Methods: Adult Wistar rats (either sex) divided into six groups. Diabetes was induced by 5 weeks combine exposure to a high-fat diet with a low dose of streptozotocin (30 mg/kg i.p.), administered on the $1^{\text {st }}$ day of starting of the $5^{\text {th }}$ week. Naringin treatment $25 \mathrm{mg} / \mathrm{kg}$ and $50 \mathrm{mg} / \mathrm{kg}$ was given simultaneously for 5 weeks. On the $36^{\text {th }}$ day, the study animals were subjected to induction myocardial ischemia-reperfusion injury induced by the ligation of the left anterior descending coronary artery ligation in anesthetizing rat. Serum glucose level and cholesterol level measured before performing of ischemic reperfusion. After reperfusion injury, the animals were sacrificed and estimate change in the heart in the course of biochemical alterations, in creatine kinase-muscle/ brain (CK-MB) and lactate dehydrogenase, lipid peroxidation (LPO), glutathione (GSH), superoxide dismutase (SOD) and infarct size in the heart.

Results and Conclusion: Naringin treatment significantly reduced the body weight, blood glucose, cholesterol, cardiac injury biomarkers, and LPO level and increased in antioxidant (GSH and SOD) level and also significantly increased in mean arterial pressure heart rate, reduced the myocardial infarction size. The present study concludes that Naringin $50 \mathrm{mg} / \mathrm{kg}$ being more prominent action to reduce the cardiotoxicity risk in ischemiareperfusion injury state and increases myocardial susceptibility through having more prominent antioxidant potential properties.

Keywords: Diabetes, Ischemia-reperfusion injury, Naringin.

(C) 2019 The Authors. Published by Innovare Academic Sciences Pvt Ltd. This is an open access article under the CC BY license (http://creativecommons. org/licenses/by/4. 0/) DOI: http://dx.doi.org/10.22159/ajpcr.2019.v12i3.30105

\section{INTRODUCTION}

Cardiovascular diseases are the major cause of death and disability in people with diabetic patients [1]. The mortality rate of the diabetic patient after coronary bypass grafting is about twice that of the non-diabetic patient [2]. The diabetic heart is more prone to develop ventricular tachyarrhythmia and high-degree atrioventricular block [3]. Diabetes mellitus increases susceptibility to ischemia-reperfusion injury and also modifies myocardial responses to ischemic conditioning strategies by disruption of intracellular signaling responsible for the enhancement of resistance to cell death $[4,5]$. Endothelial dysfunction has received increasing attention as a potential contributor to the development of vascular disease in diabetes mellitus [3]. It caused the activation of major molecular signaling mechanisms protein kinase $\mathrm{C}$, hexosamine flux, polyol pathway flux, and increased advanced glycation end product formation [6]. The diabetic heart is more sensitive for the coronary heart disease due to decreased glycolysis and alters the sarcolemmal $\mathrm{Na}^{+} / \mathrm{H}^{+}$and $\mathrm{Na}^{+} / \mathrm{Ca}^{2+}$ exchange activities and diabetic heart also increases the free fatty acid and an inflammatory mediator which is responsible for the cell damage and death during the ischemia condition [7]. Susceptibility to coronary heart disease is also increased due to the altered cardioprotective mechanism. An in vivo small rodent model for myocardial ischemia-reperfusion injury-induced damage in diabetes mellitus in which administration of high-fat diet (HFD) with a low dose of streptozotocin (STZ) and surgical occlusion of coronary artery followed by reperfusion more closely to the real clinical setting.

A therapeutic approach such as antihyperglycemic, antihyperlipidemic, and antioxidant compound can be beneficial in the prevention of cardiovascular complication associated with diabetes mellitus. Flavonoids are an important group of secondary metabolites and a source of bioactive compounds in plants. It was first discovered in the flowers of grapefruit. Naringin is major flavanone glycoside obtained from tomatoes, grapefruits, and many other citrus fruits, it presents in grape juice up to concentrations of $800 \mathrm{mg} / \mathrm{L}$. It experimentally documented to possess numerous biological properties such as antioxidant, anti-inflammatory, and antiapoptotic activities [8]. It is potential to be a useful dietary supplement in the management of the signs of metabolic syndrome. The molecular mechanism involved in the activation of the adenosine monophosphate (AMP) kinase, peroxisome proliferator-activated receptor- $\gamma$, suppressed fatty acid synthesis, and lowering blood glucose and cholesterol concentrations [9]. Naringin markedly suppressed HG-triggered cytotoxicity and apoptosis and it was suggested that contributed to cardioprotection by attenuating mitochondrial dysfunction. Naringin is a potent antioxidant effect by activation of novel antioxidant defense mechanism. It can play an important role in the management of hyperglycemia [8]. It also used in the treatment of atherosclerosis through inhibition of the HMG-CoA reductase, the release of tumor necrosis factor (TNF- $\alpha$ ), and nuclear factor- $\mathrm{k} \beta$ activation and protected against the endotoxic shock and blocked the lethal shock [10]. Naringin protects against lipopolysaccharide-induced acute lung injury in mice through suppression of iNOS activity, TNF- $\alpha$ secretion, and myeloperoxidase [11]. Experimental studies reported the protective effect of Naringin against ischemia-reperfusioninduced injury in rat [12].

On behalf of previous reports, Naringin could be a less toxic and more selective therapeutic approach for the treatment of diabetic-induced cardiovascular complications. The aim of this study was to assess whether treatment with the Naringin glycoside can prevent or mitigate the changes on infarct size, hemodynamic, and biochemical alterations in ischemia-reperfusion injury under diabetic state and its deleterious effects on cardiovascular disease. 


\section{METHODS}

\section{Drugs and chemicals}

Naringin, STZ, glutathione (GSH), and triphenyltetrazolium chloride (TTC) were purchased from Sisco Research Laboratories. Thiobarbituric acid (TBA) and dithiobis-2-nitrobenzoic acid were purchased from Himedia, Mumbai. Cholesterol kit was purchased from Erba Diagnostic and glucose, creatine kinase-muscle/brain (CK-MB), and lactate dehydrogenase (LDH) kits purchased from Reckon Diagnostic.

\section{Study animals}

The research protocol of this study has been approved by the Institutional Animal Ethics committee (IAEC) vide approval No-ASCB/ IAEC $/ 10 / 17 / 119$. Adult Wistar rats (either sex), weighing between 200 and $250 \mathrm{~g}$, were procured from registered breeder.

\section{Experimental design}

Experimental Groups-1 and 2: Rats were administered 0.9\% normal saline (p.o.) with normal chow diet and HFD was administered for 5 weeks, on the $36^{\text {th }}$ day, rats were subjected to thoracotomy and thread passed beneath the left anterior decent coronary artery (LADCA) but no ligation performed, respectively. Group-3: Rats were administered $0.9 \%$ normal saline (p.o.) with HFD was administered for 5 weeks and STZ was administered on starting of the $5^{\text {th }}$ week, on the $36^{\text {th }}$ day, rats were to LADCA ligation for $30 \mathrm{~min}$ and reperfusion for 60 min to induce myocardial I-R injury. Groups - 4 and 5: Rats were administered Naringin 25 and $50 \mathrm{mg} / \mathrm{kg}$, p.o. [9], respectively, with HFD was administered for 5 weeks and STZ was administered on starting of the $5^{\text {th }}$ week, on the $36^{\text {th }}$ day, rats were to LADCA ligation for $30 \mathrm{~min}$ and reperfusion for 60 min to induce myocardial I-R injury. Group-6: Rats were administered glibenclamide $20 \mathrm{mg} / \mathrm{kg}$, p.o. with HFD was administered for 5 weeks and STZ was administered on starting of the $5^{\text {th }}$ week, on the $36^{\text {th }}$ day, rats were to LADCA ligation for 30 min and reperfusion for $60 \mathrm{~min}$ to induce myocardial I-R injury.

\section{Induction of diabetes}

Diabetes was induced by combining exposure to an HFD with low dose of STZ. Rats were fed with high-fat containing diet (HFD) for 5 weeks and STZ was administered on starting of the $5^{\text {th }}$ week. Composition of HFD (normal chow diet $67 \%$, sucrose $20 \%$, pig lard $10 \%$, and custard powder $2.5 \%$ ) STZ was administered at a dose $30 \mathrm{mg} / \mathrm{kg}$, i.p. was prepared by freshly dissolved in $0.1 \mathrm{M}$ citrate buffer, $\mathrm{pH}$ 4.5. HFDinduced insulin resistance and STZ destroyed a portion of pancreatic $\beta$-cell. The plasma glucose was measured after $72 \mathrm{~h}$ of STZ injection (the blood samples were collected through retro-orbital plexus technique using capillary glass tube). Animal showing blood glucose more than $250 \mathrm{mg} / \mathrm{dL}$ was considered as diabetic [13].

\section{Induction of myocardial ischemic reperfusion injury}

On the $36^{\text {th }}$ day, after induction of diabetes in rat was subjected to induction of myocardial I-R. Rat was anesthetized with urethane at dose of $1.5 \mathrm{~g} / \mathrm{kg}$, i.p. and body temperature was maintained at $37^{\circ} \mathrm{C}$ using heating pad throughout the experiment. Neck was opened and tracheotomy and left thoracotomy were performed at the fifth intercostals space using rib cuter and retractor. Pericardium was opened to expose the heart and a 5/0 surgical suture attached to a $16 \mathrm{~mm}$ needle (circle cutting) was quickly placed under the left coronary artery. The animal was then stabilized for 10-15 min before the left coronary artery ligation. The left coronary artery was ligated 2-3 mm from its origin between the pulmonary artery cones and left atrium with needle-suture by pressing the polyethylene tubing against the ventricular wall. The animal then underwent $30 \mathrm{~min}$ of ischemia and reperfusion for a period of $60 \mathrm{~min}$ [13]

\section{Hemodynamic parameters measurement}

Separation of carotid artery attached with vagus nerve was done by pointed curve forceps, and then, carotid artery cannulated with polyethylene tube (internal diameter $0.30 \mathrm{~mm}$ and outer diameter $0.40 \mathrm{~mm}$ ) attached to a three-way cannula. The cannula was heparinized (Heparin $300 \mathrm{IU} / \mathrm{ml}$ ) and connected to power lab 4/30
(AD instruments, NSW, Australia) system using a pressure transducer for the measurement of hemodynamic parameters.

\section{Assessment of blood glucose, cholesterol, CKMB, and LDH level}

Blood sample was collected from the rats at end of the experimentation. The blood was collected by puncturing retro-orbital plexus under chloroform anesthesia and collected in Eppendorf tubes $(1.5 \mathrm{ml})$ and centrifuged (4000 rpm for $10 \mathrm{~min}$ ) for the estimation of glucose and cholesterol using assay kits on autoanalyzer (Microlab 300). The $2^{\text {nd }}$ time blood was collected from the carotid artery after the myocardial reperfusion procedure and prepare sample as similar above-mentioned method, and estimation of LDH and CK-MB by assay kits.

\section{Evaluation of myocardial infarct size}

The myocardial infarct size measured using TTC staining method. The heart was transversely cut to obtain slices no $>0.1 \mathrm{~cm}$ in thickness. The heart slices were placed in the glass dish containing pre-warmed (1\%) TTC in phosphate buffer solution (the $1 \%$ TTC powder diluted in a phosphate buffer). The image of TTC slices was captured with a digital camera and analyzed by Image J software [14].

\section{Studies of rat heart parameters}

Animal was sacrificed and heart tissue was removed, washed with the chilled isotonic saline, and dried with filter paper. After this heart was diced and homogenized in 0.05 chilled cold phosphate buffers. After centrifugation, supernatant was used for the analysis of antioxidant enzymes TBARS [15], GSH [16], and superoxide dismutase (SOD) [17].

\section{Statistical analysis}

All the results are expressed as mean \pm standard error of mean (SEM). The data of all the groups were analyzed by one-way ANOVA followed by Tukey's multiple comparison tests using software GraphPad Prism. A value of $\mathrm{p}<0.05$ was considered to be statistically significant.

\section{RESULTS}

\section{Effect of Naringin on body weight}

Diabetic control rats show significant $(p<0.05)$ increase in body weight in the $1^{\text {st }}$ and $5^{\text {th }}$ weeks and significantly $(\mathrm{p}<0.001)$ gain in body weight $2^{\text {nd }}-4^{\text {th }}$ weeks as compare to sham control groups. On treatment with Naringin $(25 \mathrm{mg} / \mathrm{kg})$, a significant $(\mathrm{p}<0.05)$ decreased in body weight in the $3^{\text {rd }}$ and $5^{\text {th }}$ weeks, as well as similar treatment significant $(\mathrm{p}<0.01)$ decreased but maintained body weight in final $4^{\text {th }}$ week as compare to diabetic I-R rats. On treatment with Naringin $(50 \mathrm{mg} / \mathrm{kg})$, a significant $(p<0.01)$ decreased but maintained body weight was observed in the $1^{\text {st }}$ week, further observe $(\mathrm{p}<0.001)$ over the duration of the $2^{\text {nd }}-5^{\text {th }}$ weeks as compared to diabetic IR rats. Treatment with the standard glibenclamide $(20 \mathrm{mg} / \mathrm{kg})$, a significant $(\mathrm{p}<0.05)$ decreased but maintained body weight was observed in the $1^{\text {st }}$ week, further observe a decrease in body weight $(\mathrm{p}<0.001)$ over the duration of the $2^{\text {nd }}-$ $5^{\text {th }}$ weeks as compared to diabetic IR rats.

Following the injection of STZ (dose) on day 1 of the $5^{\text {th }}$ week, decrease in body weight of diabetic control and diabetic IR rats was observed, but STZ (dose) administration did not alter body weight or weight gain in the Naringin ( 25 and $50 \mathrm{mg} / \mathrm{kg}$ ) and glibenclamide $(20 \mathrm{mg} / \mathrm{kg})$ treated rats in final week as compared to diabetic IR rats (Fig. 1).

\section{Effect of Naringin on water intake}

Diabetic control rats show significant $(\mathrm{p}<0.001)$ increase in water intake over the duration of 5 weeks as compared to the sham control group. The water intake significant $(\mathrm{p}<0.05)$ reduces in Naringin $(25 \mathrm{mg} / \mathrm{kg})$ treated rats in the $1^{\text {st }}$ and $3^{\text {rd }}$ weeks and also significantly $(\mathrm{p}<0.01)$ increased in water intake at the $4^{\text {th }}$ week, as well as similar treatment significant $(\mathrm{p}<0.001)$ decreased over the duration of the $2^{\text {nd }}$ and $5^{\text {th }}$ weeks as compare to diabetic I-R rats. Naringin $50 \mathrm{mg} / \mathrm{kg}$ and glibenclamide $20 \mathrm{mg} / \mathrm{kg}$ treated rats show significant $(\mathrm{p}<0.001)$ increase in water intake over the duration of the $5^{\text {th }}$ week as compared to diabetic I-R control rats (Fig. 2). 


\section{Effect of Naringin on feed intake}

Diabetic control rats show significant $(p<0.05)$ increase in feed intake in the $2^{\text {nd }}$ week and also increase $(\mathrm{p}<0.01)$ in feed intake over the duration of the $3^{\text {rd }}$ and $5^{\text {th }}$ weeks, as well as similar treatment significant $(\mathrm{p}<0.001)$ increase over the duration of the $4^{\text {th }}$ week compare to sham control groups. On treatment with Naringin $(50 \mathrm{mg} / \mathrm{kg})$, a significant $(\mathrm{p}<0.05)$ decreased in feed intake over the duration of the $2^{\text {nd }}$ and $5^{\text {th }}$ weeks and also decreased $(\mathrm{p}<0.01)$ in the $3^{\text {rd }}$ week, as well as significantly decreased $(\mathrm{p}<0.001)$ in the $4^{\text {th }}$ week as compared to diabetic IR rats (Fig. 3 ).

Effect of Naringin on blood glucose and cholesterol level, CK-MB, and LDH

Blood glucose and cholesterol level were significant $(\mathrm{p}<0.001)$ increase in diabetic rats as compared to sham control group. Naringin 25 and $50 \mathrm{mg} / \mathrm{kg}$, p.o.) and glibenclamide (20 mg/kg, p.o.) treated rats show significant $(\mathrm{p}<0.001)$ decrease in glucose level, as compare to diabetic I-R control rats. Cholesterol level was significantly $(\mathrm{p}<0.001)$ decreased in Naringin-treated rats $(25$ and $50 \mathrm{mg} / \mathrm{kg}$, p.o.), as compared to diabetic I-R control rats. The level of CK-MB and LDH was significantly elevated $(p<0.001)$ in diabetic rats as compared to sham control group. Remarkably, CK-MB and LDH level were elevated significantly $(\mathrm{p}<0.001)$ in diabetic I-R rats as compare to diabetic control rats. Naringin low and high dose and reference drug glibenclamide-treated rats CK-MB and LDH level was significantly $(\mathrm{p}<0.001)$ decreased as compared to the diabetic I-R control group. Naringin $50 \mathrm{mg} / \mathrm{kg}$ treated rats show significantly $(\mathrm{p}<0.001)$ decreased cholesterol and LDH level as compare to glibenclamide-treated rats (Table 1).

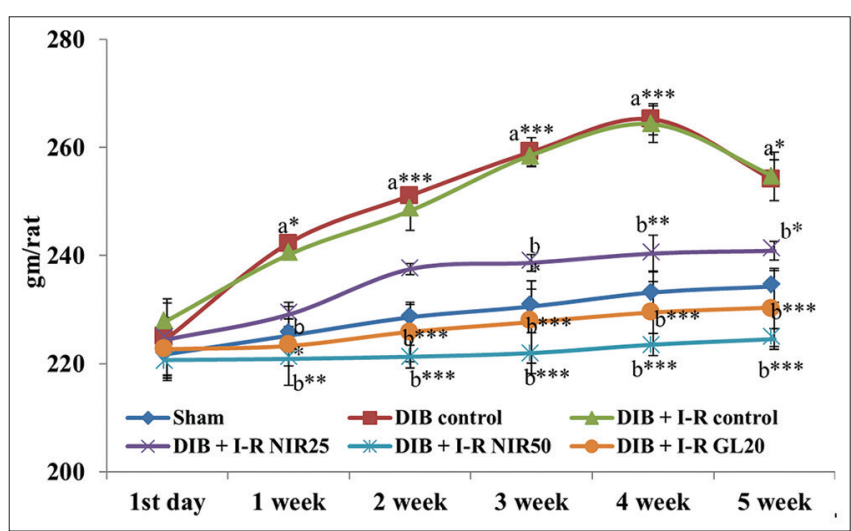

Fig. 1: Effect of Naringin on body weight. Value is expressed as mean \pm SEM. $n=6 ;(a) *(p<0.05),{ }^{* * *}(\mathbf{p}<0.001)$ versus sham control group; (b) $*(\mathbf{p}<0.05), * *(\mathbf{p}<0.01), * * *(\mathbf{p}<0.001)$ versus diabetic I-R control group (One-way ANOVA followed by Tukey's test)

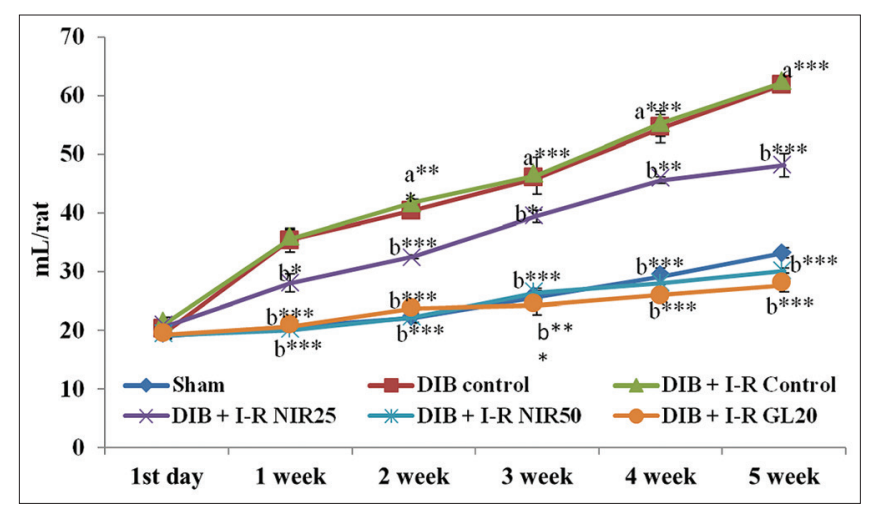

Fig. 2: Effect of Naringin on water intake.

Value is expressed as mean \pm SEM. $n=6 ;(a) *(p<0.05), * * *(p<0.001)$ versus sham control group; (b) ${ }^{*}(p<0.05),{ }^{* *}(p<0.01)$,

*** $(\mathbf{p}<0.001)$ versus diabetic I-R control group (One-way ANOVA followed by Tukey's test)
Effect of Naringin on biochemical estimations (TBARS, GSH, and SOD level)

TBARS activity significantly $(\mathrm{p}<0.001)$ increased and GSH and SOD level significantly $(\mathrm{p}<0.001)$ decreased in diabetic control rats and as compared to the sham control group. As similar manner, more potentially TBARS level significantly $(\mathrm{p}<0.001)$ increased and GSH and SOD activity significantly $(\mathrm{p}<0.05, \mathrm{p}<0.001)$ decreased, respectively, in diabetic I-R control rats as compared to diabetic control rats. Naringin 25 and $50 \mathrm{mg} / \mathrm{kg}$, p.o. treated group showed significantly $(\mathrm{p}<0.001)$ decreased TBARS, GSH level, and SOD activity as compared to diabetic I-R. Glibenclamide-treated group showed significantly $(\mathrm{p}<0.001)$ decreased GSH level and SOD activity as compared to diabetic I-R. Naringin $50 \mathrm{mg} / \mathrm{kg}$ treated rats show significantly $(\mathrm{p}<0.001)$ decreased TBARS, GSH level, and SOD activity as compared to glibenclamidetreated rats (Table 2).

\section{Effect of Naringin on hemodynamic evaluation}

A significant $(\mathrm{p}<0.001)$ decrease in arterial pressure, significant $(p<0.01)$ elevation in the heart rate $(H R)$, and significant $(p<0.001)$ elevation in the systolic arterial pressure (SAP) and diastolic arterial pressure (DAP) were observed in the diabetic control group when compared to sham control group. Significant $(\mathrm{p}<0.001)$ decreased in SAP, DAP, mean arterial pressure (MAP), and HR in diabetic I-R control rats as compared to diabetic control rats. On treatment with Naringin 25 and $50 \mathrm{mg} / \mathrm{kg}$ significantly $(\mathrm{p}<0.001)$ restore AP as compared to diabetic I-R control group. Naringin $50 \mathrm{mg} / \mathrm{kg}$ treated rats significant $(p<0.05)$ restore MAP and HR as compared to diabetic I-R control. Glibenclamide-treated rats show significant $(\mathrm{p}<0.001)$ restore AP, and also significant $(\mathrm{p}<0.01)$ restore the SAP, DAP, and MAP and significantly $(p<0.05)$ restore the HR when compared to diabetic I-R group (Table 3$)$.

\section{Effect of Naringin on infarct size in rat heat}

The infarct size was significantly increased diabetic control groups as compared to the sham control group. Infarct size was significantly increased diabetic I-R control groups as compared to the diabetic control group. Naringin $(50 \mathrm{mg} / \mathrm{kg}$, p.o.) and glibenclamide $(20 \mathrm{mg} / \mathrm{kg}$, p.o.) treated groups show significantly reduced the infarct size as compared to the diabetic I-R group (Fig. 4).

\section{DISCUSSION}

Diabetes mellitus is a rapidly growing health concern which causes several cardiovascular complications including ischemic heart disease, diabetic cardiomyopathy, and stroke [2,3]. The relative risk of ischemic heart disease in the diabetic population is more vulnerable compare that in the non-diabetic population [5]. The enhanced susceptibility is partially due to an associated metabolic disorder characterized by high blood glucose, insulin resistance, and dyslipidemia in patients with diabetic, which aggravated myocardial injury after myocardial ischemia-reperfusion $[3,16]$. The proposed model combination of HFD with a low dose of STZ-treated rat after that performed myocardial ischemic reperfusion (I-R) injury-induced damage in diabetes animals; it is surgical occlusion of coronary artery followed by reperfusion more closely to the real clinical setting. Recently, tend to focus on; search for new cardioprotective molecules have targeted as well as less complication in therapy. In this contest, the present study was undertaken to explore the cardioprotective effect of Naringin on ischemia-reperfusion injury in a diabetic rat model.

In the study, animal treated with HFD-STZ increases feed intake, water intake, and body weight was found to be significantly elevated, due to increased intake of feed. Linked with weight gain in a hyperglycemic state, glucose from the blood cannot enter the cells due to an abnormality of diabetes associated dysfunction with that body cannot convert the energy from food this condition feel lack of energy and causes an increase in hunger [18]. Increase in body weight and fat deposition is the chief indicators for the gradual progress of metabolic abnormalities and onset of obesity. Naringin-treated rats reduced and maintained feed intake, water intake, and body weight as compared to diabetic I-R control rats' 
Table 1: Effect of Naringin on blood parameters (glucose and cholesterol, CK-MB, and LDH)

\begin{tabular}{llll}
\hline Group & Glucose & Cholesterol & CK-MB \\
\hline Sham & $88.3 \pm 3.28$ & $60.3 \pm 2.51$ & $65.17 \pm 1.78$ \\
DIB control & $331.0 \pm 7.49 \mathrm{a}^{* * *}$ & $180.0 \pm 2.38 \mathrm{a}^{* * *}$ & $87.33 \pm 3.69 \mathrm{a}^{* * *}$ \\
DIB I-R control & $330.1 \pm 7.61$ & $181.8 \pm 2.60$ & $121.20 \pm 2.21 \mathrm{~b}^{* * *}$ \\
NIR $25 \mathrm{mg} / \mathrm{kg}$ & $170.0 \pm 8.66 \mathrm{c}^{* * *}$ & $113.0 \pm 1.75 \mathrm{c}^{* * *}$ & $76.17 \pm 1.30 \mathrm{c}^{* * *}$ \\
NIR $50 \mathrm{mg} / \mathrm{kg}$ & $105.5 \pm 2.58 \mathrm{c}^{* * *}$ & $80.3 \pm 3.79 \mathrm{c}^{* * *}, \mathrm{~d}^{* * *}$ & $810 \pm 2.94 \mathrm{~b}^{* * *}$ \\
GL $20 \mathrm{mg} / \mathrm{kg}$ & $91.5 \pm 2.05 \mathrm{c}^{* * *}$ & $176.7 \pm 1.36$ & $38.67 \pm 2.23 \mathrm{c}^{* * *}$ \\
\hline
\end{tabular}

Values are expressed as mean \pm SEM. $\mathrm{n}=6$; (a) ${ }^{* * *}(\mathrm{p}<0.001)$ versus sham control; (b) ${ }^{* * *}(\mathrm{p}<0.001)$ versus diabetic control group; (c) ${ }^{* * *}(\mathrm{p}<0.001)$ versus diabetic I-R control group; $(\mathrm{d}) * * *(\mathrm{p}<0.001)$ versus glibenclamide $20 \mathrm{mg} / \mathrm{kg}$ (One-way ANOVA followed by Tukey's test). CK-MB: Creatine kinase-muscle/brain, LDH: Lactate dehydrogenase

Table 2: Effect of Naringin on TBARS, GSH, and SOD level

\begin{tabular}{|c|c|c|c|}
\hline Group & TBARS & GSH & SOD \\
\hline Sham & $5.90 \pm 0.16$ & $15.45 \pm 0.87$ & $9.63 \pm 0.27$ \\
\hline DIB control & $21.93 \pm 0.37 \mathrm{a}^{* * *}$ & $5.48 \pm 0.37 a^{* * *}$ & $4.32 \pm 0.11 \mathrm{a}^{* * *}$ \\
\hline DIB I-R control & $31.81 \pm 0.16 b^{* * *}$ & $2.84 \pm 0.53 \mathrm{~b}^{*}$ & $2.78 \pm 0.28 b^{* * *}$ \\
\hline NIR 25 mg/kg & $12.87 \pm 0.15 c^{* * *}, d^{* * *}$ & $6.59 \pm 0.47 c^{* * *}$ & $5.26 \pm 0.08 c^{* * *}$ \\
\hline NIR 50 mg/kg & $11.65 \pm 0.90 c^{* * *}, d^{* * *}$ & $14.73 \pm 0.56 c^{* * *}, d^{* * *}$ & $14.45 \pm 0.13 c^{* * *}, d^{* * *}$ \\
\hline GL $20 \mathrm{mg} / \mathrm{kg}$ & $27.60 \pm 0.46$ & $10.17 \pm 0.22 \mathrm{c}^{* * *}$ & $6.93 \pm 0.19 c^{* * *}$ \\
\hline
\end{tabular}

Values are expressed as mean \pm SEM. $\mathrm{n}=6$; (a) ${ }^{* * *}(\mathrm{P}<0.001)$ versus sham control; $(\mathrm{b}){ }^{*}(\mathrm{p}<0.05)^{* * *}(\mathrm{p}<0.001)$ versus diabetic control group; $(\mathrm{c}){ }^{* * *}(\mathrm{p}<0.001)$ versus diabetic I-R control group; (d) ***(p<0.001) versus glibenclamide $20 \mathrm{mg} / \mathrm{kg}$ (One-way ANOVA followed by Tukey's test). GSH: Glutathione, SOD: Superoxide dismutase

Table 3: Effect of Naringin on hemodynamic parameters

\begin{tabular}{lllll}
\hline Groups & AP & SAP & DAP & MAP \\
\hline Sham & $115.7 \pm 1.65$ & $124.3 \pm 1.36$ & $84.67 \pm 1.09$ & $97.88 \pm 1.46$ \\
DIB control & $88.33 \pm 4.56 \mathrm{a}^{* * *}$ & $140.5 \pm 1.40 \mathrm{a}^{* * *}$ & $106.5 \pm 1.85 \mathrm{a}^{* * *}$ & $117.5 \pm 1.86 \mathrm{a}^{* * *}$ \\
DIB I-R control & $85.50 \pm 2.49$ & $117.3 \pm 2.51 \mathrm{~b}^{* * *}$ & $77.83 \pm 1.86 \mathrm{~b}^{* * *}$ & $91.52 \pm 2.55 \mathrm{~b}^{* * *}$ \\
NIR 25 mg/kg & $104.0 \pm 3.05 \mathrm{c}^{* * *}$ & $118.1 \pm 0.97$ & $78.50 \pm 2.33$ & $430.7 \pm 1.55 \mathrm{a}^{* *}$ \\
NIR $50 \mathrm{mg} / \mathrm{kg}$ & $109.2 \pm 1.31 \mathrm{c}^{* * *}$ & $121.1 \pm 0.68$ & $82.25 \pm 0.92$ & $91.7 \pm 1.03$ \\
GL 20 $\mathrm{mg} / \mathrm{kg}$ & $114.4 \pm 2.08 \mathrm{c}^{* * *}$ & $123.6 \pm 0.57 \mathrm{c}^{* *}$ & $83.16 \pm 0.69 \mathrm{c}^{* *}$ & $95 \pm 0.98 \mathrm{c}^{*}$ \\
\hline
\end{tabular}

Values are expressed as mean \pm SEM. $\mathrm{n}=6$; (a) ${ }^{* *}(\mathrm{p}<0.01),{ }^{* * *}(\mathrm{p}<0.001)$ versus sham control; $(\mathrm{b}){ }^{* * *}(\mathrm{p}<0.001)$ versus diabetic control group; $(\mathrm{c}) *(\mathrm{p}<0.05),{ }^{* *}(\mathrm{p}<0.01)$,

${ }_{* * *}(\mathrm{p}<0.001)$ versus diabetic I-R control group (One-way ANOVA followed by Tukey's test). AP: Arterial pressure, SAP: Systolic arterial pressure, DAP: Diastolic arterial pressure, MAP: Mean arterial pressure, HR: Heart rate

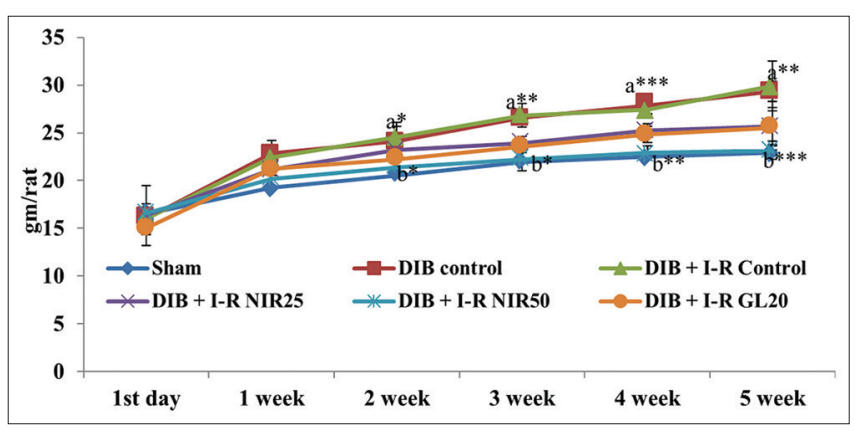

Fig. 3: Effect of Naringin on feed intake. Value is expressed as mean \pm SEM. $\mathrm{n}=6$; (a) $*(\mathbf{p}<0.05), * * *(\mathrm{p}<0.001)$ versus sham control group; (b) ${ }^{*}(\mathrm{p}<0.05),{ }^{* *}(\mathrm{p}<0.01),{ }^{* * *}(\mathrm{p}<0.001)$ versus diabetic I-R control group (One-way ANOVA followed by Tukey's test)

results are in agreement with other experimental studies [19].

Various studies have reported that I-R injury sequence results in the generation of free radicals in the myocardium [5,7]. Ischemia reduced the activity of cellular defense systems against free radicals and reperfusion or restoration of oxygen further disturbs the delicate balance of oxidants/antioxidants and generates a burst of free radicals in the tissue [20]. Numerous studies suggested that increased oxidative stress, generation of reactive oxygen species (ROS), and imbalance in antioxidant and oxidant contribute to myocardial tissue injury which explains the decreased in heart weight due to myocardial loss $[6,21]$. The oxidative indicators GSH and SOD involved in heart disease have

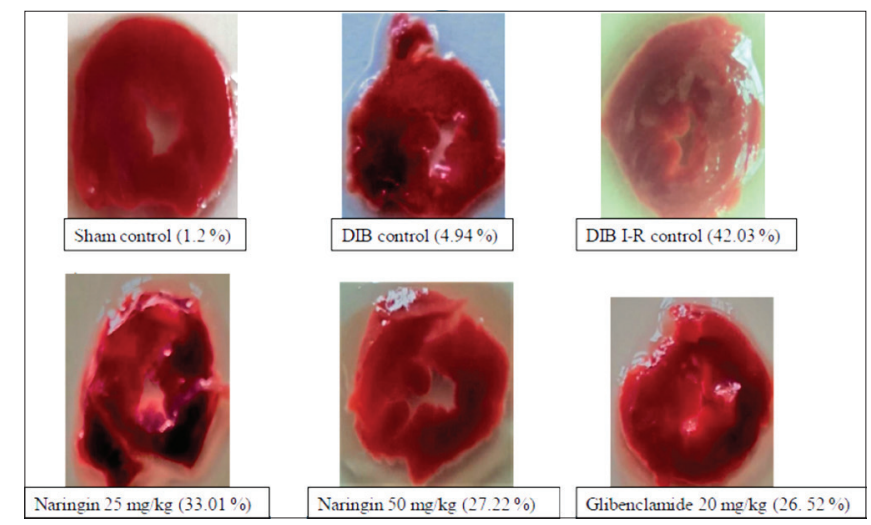

Fig. 4: Effect of Naringin on infarct size in rat heart

been previously reported [22]. Diabetic heart accelerates myocardial oxidative stress and subsequently aggravates heart damage and secondary to lead ischemia-reperfusion injury [5]. Hyperglycemia decreased the antioxidant capacity by reducing SOD and GSH activities [23]. We have observed decreased GSH and SOD level in the study group treated with a combination of HFD and a low dose of STZ plus I-R injury. In addition, HFD-STZ rats significantly increased the cardiac damaged enzymes level (CK-MB and LDH) possible indication of the increased severity of myocardial damage. It has been shown that the enhancement of CK-MB level and LDH attributed to the overproduction of free radicals and cell membrane injury that might have led to the release of cardiac toxic biomarkers [24]. Naringin 
activates AMP-activated protein kinase and hypolipidemic effect due to reducing the HMG-CoA reductase $[9,10]$. Feeding Naringin could downregulate the expression of gluconeogenic enzymes and result in lower blood glucose concentration [19]. Reduction of glucose level and cholesterol level in Naringin treatment confirms in the study. In agreement with these reports, treatment with Naringin significantly increased the activities of SOD and GSH and decreased the levels of MDA in heart and reduced CK-MB and LDH levels were reverted to normal which shows the protective effect of Naringin through maintenance of cell integrity and prevented cell injury and protect the myocardium. LDH level in Naringin-treated groups shown its potential to reduce oxidative, intracellular $\mathrm{Ca}^{2+}$ overload, inflammation, and hyperglycemia-induced ischemia-reperfusion injury and our results are in accordance with other experimental reports [25]. Observed that in Naringin treatment preserve near to normal heart muscle architecture, and reduced to infarct size. The data showed that Naringin is capable of limiting infarct size when administered before the onset of ischemiareperfusion and has shown cardioprotection in diabetes-induced myocardial I-R injury. Hyperglycemia condition associated with I-R, potentiate ROS generation increased the HR responsible for increased myocardial oxygen consumption and demand which leads to ischemic necrosis of the myocardium in animal [26,27]. Naringin treatment will help to preserve near normal heart functions, these were reflected by near normal the underlying the cardioprotective mechanisms effects of Naringin against diabetic IR-induced abnormality. There is evidence for an association between high dietary intakes of Naringin reduction of cardiac damage.

\section{CONCLUSION}

Therefore, the present study suggests a protective effect of Naringin at a higher dose on HFD-STZ-induced diabetes with myocardial ischemic reperfusion injury in rats. Naringin $50 \mathrm{mg} / \mathrm{kg}$ shown protected significantly for all parameters and it has a best effective dose. Further, we have concluded that Naringin at higher dose level effectively reduced the body weight it also reduced the blood glucose level and cholesterol level and showed a significant result in biochemical parameters, which effectively reduced the lipid peroxidation level and increased the GSH and SOD level and also shown significant result in hemodynamic parameters, MAP and HR. Naringin pre-treatment also reduced the myocardial infarction percentage and damage.

\section{AUTHORS' CONTRIBUTIONS}

All authors have equal contribution to this manuscript. The study conception and experimental design by Ajay Singh Kushwah, acquisition of data and drafting of manuscript analysis, and interpretation of data by Neelam Kumari.

\section{CONFLICTS OF INTEREST}

There are no conflicts of interest.

\section{REFERENCES}

1. Al-Nozha MM, Ismail HM, Al Nozha OM. Coronary artery disease and diabetes mellitus. J Taibah Univ Med Sci 2016;11:330-8.

2. Paulson DJ. The diabetic heart is more sensitive to ischemic injury. Cardiovasc Res 1997;34:104-12.

3. Patel AC, Pathak LN, Bhatt N, Marya B, Gavania M, Trivedi H. Review: Cardio vascular cmplication of diabetes mellitus. J Appl Pharm Sci 2011;1:1-6.

4. Forbes JM, Cooper ME. Mechanism of diabetic complication. Physiol Rev 2013;93:137-88.

5. Lejay A, Fang F, John R, Van JA, Barr M, Thaveau F, et al. Ischemia reperfusion injury, ischemia conditioning and diabetes mellitus. J Mol
Cell Cardiol 2016;91:11-22.

6. Giacco F, Brownlee M. Oxidative stress and diabetic complications. Circ Res 2010;107:1058-70.

7. Hoffman JW Jr., Gilbert TB, Poston RS, Silldorff EP. Myocardial reperfusion injury: Etiology, mechanisms, and therapies. J Extra Corpor Technol 2004;36:391-411

8. Bharti S, Rani N, Krishnamurthy B, Arya DS. Preclinical evidence for the pharmacological actions of naringin: A review. Planta Med 2014;80:437-51.

9. Alam MA, Kauter K, Brown L. Naringin improves diet-induced cardiovascular dysfunction and obesity in high carbohydrate, high fat diet-fed rats. Nutrients 2013;5:637-50.

10. Cao X, Lin W, Liang C, Zhang D, Yang F, Zhang Y, et al. Naringin rescued the TNF- $\alpha$-induced inhibition of osteogenesis of bone marrowderived mesenchymal stem cells by depressing the activation of NF-KB signaling pathway. Immunol Res 2015;62:357-67.

11. Liu Y, Wu H, Nie YC, Chen JL, Su WW, Li PB, et al. Naringin attenuates acute lung injury in LPS-treated mice by inhibiting NF-KB pathway. Int Immunopharmacol 2011;11:1606-12.

12. Singh D, Chopra K. The effect of naringin, a bioflavonoid on ischemiareperfusion induced renal injury in rats. Pharmacol Res 2004;50:187-93.

13. Fu F, Tian F, Zhou H, Lv W, Tie R, Ji L, et al. Semen cassiae attenuates myocardial ischemia and reperfusion injury in high-fat diet streptozotocin-induced Type 2 diabetic rats. Am J Chin Med 2014;42:95-108.

14. Ito WD, Schaarschmidt S, Klask R, Hansen S, Schäfer HJ, Mathey D, et al. Infarct size measurement by triphenyltetrazolium chloride staining versus in vivo injection of propidium iodide. J Mol Cell Cardiol 1997:29:2169-75.

15. Ohkawa H, Ohishi N, Yagi K. Assay for lipid peroxides in animal tissues by thiobarbituric acid reaction. Anal Biochem 1979;95:351-8.

16. Ellman GL. Tissue sulfhydryl groups. Arch Biochem Biophys 1959:82:70-7.

17. Kono Y. Generation of superoxide radical during autoxidation of hydroxylamine and an assay for superoxide dismutase. Arch Biochem Biophys 1978;186:189-95.

18. Kahn SE, Hull RL, Utzschneider KM. Mechanisms linking obesity to insulin resistance and Type 2 diabetes. Nature 2006;444:840-6.

19. Pu P, Gao DM, Mohamed S, Chen J, Zhang J, Zhou XY, et al. Naringin ameliorates metabolic syndrome by activating AMP-activated protein kinase in mice fed a high-fat diet. Arch Biochem Biophys 2012;518:61-70.

20. Galiñanes M, Fowler AG. Role of clinical pathologies in myocardial injury following ischaemia and reperfusion. Cardiovasc Res 2004;61:512-21

21. Ramezani-Aliakbari F, Badavi M, Dianat M, Mard SA, Ahangarpour A. Effects of gallic acid on hemodynamic parameters and infarct size after ischemia-reperfusion in isolated rat hearts with alloxan-induced diabetes. Biomed Pharmacother 2017;96:612-8.

22. Abdelhalim AT, Nur NM, Mansour S, Ibrahim A. Cardioprotective effect of Vitamin E against myocardial infarction induced by isoprenaline in albino rats. Asian J Pharm Clin Res 2018;11:273-6.

23. Pieme CA, Tatangmo JA, Simo G, Biapa Nya PC, Ama Moor VJ, Moukette Moukette B, et al. Relationship between hyperglycemia, antioxidant capacity and some enzymatic and non-enzymatic antioxidants in african patients with Type 2 diabetes. BMC Res Notes 2017:10:141.

24. Hegde K, Patel D, Varma K. Evaluation of cardioprotective activity of aqueous extract of Garcinia indica Linn fruit rind. Asian J Pharm Clin Res 2015;8:107-12.

25. You Q, Wu Z, Wu B, Liu C, Huang R, Yang L, et al. Naringin protects cardiomyocytes against hyperglycemia-induced injuries in vitro and in vivo. J Endocrinol 2016;230:197-214.

26. Ansley DM, Wang B. Oxidative stress and myocardial injury in the diabetic heart. J Pathol 2013;229:232-41.

27. Pan GZ, Xie J, Tian XF, Yang SW, Zhou YJ. The impact of different plasma glucose levels on heart rate in experimental rats with acute myocardial infarction. Cardiol Res 2016;7:146-51. 